Article

\title{
Female Specific Association of Low Insulin-Like Growth Factor 1 (IGF1) Levels with Increased Risk of Premature Mortality in Renal Transplant Recipients
}

\author{
Frank Klont ${ }^{1, *(D)}$, Lyanne M. Kieneker ${ }^{2}$, Antonio W. Gomes-Neto ${ }^{2}$, Suzanne P. Stam ${ }^{2} \mathbb{D}$, \\ Nick H. T. ten Hacken ${ }^{3}$, Ido P. Kema ${ }^{4}$, André P. van Beek ${ }^{5}{ }^{\circledR}$, Else van den Berg ${ }^{2}$, \\ Péter Horvatovich ${ }^{1}\left(\mathbb{D}\right.$, Rainer Bischoff ${ }^{1}$ (D) and Stephan J. L. Bakker ${ }^{2} \mathbb{D}$ \\ 1 Department of Analytical Biochemistry, Groningen Research Institute of Pharmacy, University of Groningen, \\ 9713 AV Groningen, The Netherlands; P.L.Horvatovich@rug.nl (P.H.); r.p.h.bischoff@rug.nl (R.B.) \\ 2 Department of Internal Medicine, Division of Nephrology, University Medical Center Groningen, \\ University of Groningen, 9700 RB Groningen, The Netherlands; 1.m.kieneker@umcg.nl (L.M.K.); \\ a.w.gomes.neto@umcg.nl (A.W.G.-N.); s.p.stam@umcg.nl (S.P.S.); elsevandenberg@hotmail.com (E.v.d.B.); \\ s.j.l.bakker@umcg.nl (S.J.L.B.) \\ 3 Department of Pulmonary Diseases, University Medical Center Groningen, University of Groningen, \\ 9700 RB Groningen, The Netherlands; n.h.t.ten.hacken@umcg.nl \\ 4 Department of Laboratory Medicine, University Medical Center Groningen, University of Groningen, \\ 9700 RB Groningen, The Netherlands; i.p.kema@umcg.nl \\ 5 Department of Endocrinology, University Medical Center Groningen, University of Groningen, \\ 9700 RB Groningen, The Netherlands; a.p.van.beek@umcg.nl \\ * Correspondence: klont.frank@gmail.com
}

Received: 19 December 2019; Accepted: 17 January 2020; Published: 21 January 2020

\begin{abstract}
Associations between insulin-like growth factor 1 (IGF1) and mortality have been reported to be female specific in mice and in human nonagenarians. Intervention in the growth hormone (GH)-IGF1 axis may particularly benefit patients with high risk of losing muscle mass, including renal transplant recipients (RTR). We investigated whether a potential association of circulating IGF1 with all-cause mortality in stable RTR could be female specific and mediated by variation in muscle mass. To this end, plasma IGF1 levels were measured in 277 female and 343 male RTR by mass spectrometry, and their association with mortality was assessed by Cox regression. During a median follow-up time of 5.4 years, 56 female and 77 male RTR died. In females, IGF1 was inversely associated with risk (hazard ratio (HR) per 1-unit increment in log2-transformed (doubling of) IGF1 levels, 95\% confidence interval $(\mathrm{CI}))$ of mortality $(0.40,0.24-0.65 ; p<0.001)$, independent of age and the estimated Glomerular filtration rate (eGFR). In equivalent analyses, no significant association was observed for males $(0.85,0.56-1.29 ; p=0.44)$, for which it should be noted that in males, age was negatively and strongly associated with IGF1 levels. The association for females remained materially unchanged upon adjustment for potential confounders and was furthermore found to be mediated for $39 \%$ by $24 \mathrm{~h}$ urinary creatinine excretion. In conclusion, low IGF1 levels associate with an increased risk of all-cause mortality in female RTR, which may link to conditions of low muscle mass that are known to be associated with poor outcomes in transplantation patients. For males, the strongly negative association of age with IGF1 levels may explain why low IGF1 levels were not found to be associated with an increased risk of all-cause mortality.
\end{abstract}

Keywords: insulin-like growth factor 1; growth hormone; muscle mass; patient survival; physical activity; renal transplant recipients 


\section{Introduction}

The peptide hormone insulin-like growth factor 1 (IGF1) is a key mediator of the biochemical/endocrine effects of growth hormone (GH) [1]. Synthesis of IGF1 is regulated by GH and mainly takes place in the liver after which IGF1 is secreted and transported to other tissues, where it acts as an endocrine hormone [2,3]. IGF1 provides a stable, integrated measure of the activity of the somatotropic axis thereby contrasting with GH secretion which is highly variable [3].

Reduced GH and IGF1 signaling extends lifespan in many laboratory models, including worms, yeast, and drosophila [4]. A specific role for IGF1 receptor signaling in mammalian longevity was first established in IGF1 receptor-(haplo) insufficient mice. These mice lived 33\% longer than their wildtype littermates, yet this effect was restricted to females [5], which was subsequently confirmed in two follow-up studies in mice [6,7]. A similar link between IGF1 receptor-insufficiency and longevity has been proposed for humans following observations in several studies [8-10]. Moreover, IGF1 levels predict better survival in nonagenarians (i.e., people between the age of 90 and 99), and, notably, the corresponding association between IGF1 levels and longevity was found to be female specific [11]. It remains, however, unclear whether circulating levels of IGF1 are also associated with longevity in middle-aged subjects and whether such association is female specific.

Studying the association between IGF1 levels and longevity (survival) in specific patient groups appears to be interesting as well, for example, following the growing interest in ghrelin receptor agonists targeting the GH-IGF1 axis to potentially reverse the anorexia-cachexia syndrome in a variety of conditions, including renal insufficiency [12-15]. An important mechanism by which stimulation of the GH-IGF1 axis may improve long-term outcome is through stimulation of muscle mass accretion $[15,16]$. To this regard, a large and growing group of patients that might be worthwhile studying is that of renal transplant recipients (RTR), in which protein-energy wasting is always lurking [17-19]. In fact, it has been found that the risk of premature mortality in this population is 6-7 times higher compared to the general population [20], and this risk was particularly high in RTR with low muscle mass, as reflected by low $24 \mathrm{~h}$ urinary creatinine excretion [21,22]. Recent studies furthermore suggested that $24 \mathrm{~h}$ urinary creatinine excretion may be a noninvasive, easily accessible, inexpensive, and direct measurement of total body muscle mass [19], while this measure is often not included in clinical studies to complement the imaging technique armamentarium which is applied for evaluation of muscle mass in observational and clinical intervention studies [23-25].

In this study, we aimed to investigate (1) the nature of the association between circulating levels of IGF1 and mortality in RTR, (2) whether such (potential) association is female specific, and (3) furthermore whether such (potential) association could, in part or as a whole, be mediated by variation in muscle mass, as reflected by $24 \mathrm{~h}$ urinary creatinine excretion.

\section{Experimental Section}

\subsection{Study Population}

All RTR (aged $\geq 18$ years) that were transplanted at the University Medical Center Groningen (UMCG) and that were one year or longer post-transplantation were approached for participation in this study during outpatient clinic visits between 2008 and 2010, as described previously [26]. The RTR included in this study had no known or apparent systemic diseases (e.g., malignancies, active infections) at inclusion. Written informed consent was obtained from $707(87 \%)$ of the 817 RTR that were initially invited, and plasma IGF1 levels were measured in 620 RTR (76\%). For this study, ethical approval has been granted by the UMCG's review board (METc 2008/186), and the study adheres to the Declaration of Helsinki. The study is registered as 'TransplantLines Food and Nutrition Biobank and Cohort Study (TxL-FN)' at ClinicalTrials.gov (NCT identifier 'NCT02811835'). 


\subsection{Data and Sample Collection}

Measurement of clinical parameters has been described in detail previously [26]. Physical activity was assessed with the Short QUestionnaire to ASsess Health-enhancing physical activity (SQUASH) as developed and validated by the Dutch National Institute of Public Health and Environment to assess daily life physical activity in the Dutch adult population [27]. Information on medical history and medication use was obtained from patient records. Diabetes was defined as the use of antidiabetic medication or fasting plasma glucose of at least $7.0 \mathrm{mmol} / \mathrm{L}$. Twenty-four $\mathrm{h}$ urine was collected (per strict protocol) a day before the outpatient clinic visits while blood was drawn in the morning on the day of the outpatient clinic visit, yet after completion of the $24 \mathrm{~h}$ urine collection.

\subsection{Laboratory Procedures}

Blood and urine markers were measured by routine laboratory procedures with the exception of serum creatinine which was assessed using a modified version of the Jaffé method (MEGA AU 510; Merck Diagnostica, Darmstadt, Germany), and the urine total protein concentration which was obtained using the Biuret reaction (MEGA AU 510; Merck Diagnostica). Renal function was estimated with the 2012 Chronic Kidney Disease Epidemiology (CKD-EPI) Collaboration equation using both serum creatinine and cystatin C [28]. IGF1 was assessed in plasma samples (which had not undergone any previous freeze-thaw cycle) using a semi-automated mass spectrometric IGF1 assay [29] which was validated according to FDA guidelines [30]. The samples were analyzed in 13 analytical runs containing up to 81 clinical samples per run, as well as nine calibration samples and duplicate quality control (QC) samples at three concentrations (i.e., low, midrange, and high IGF1 levels). All runs met the acceptance criteria stipulated in the FDA guidelines thereby featuring 75\% (though at least six) of the calibration samples with back-calculated levels within 15\% (or 20\% for the lowest level calibration sample) of their expected value, and at least $67 \%$ of the QC samples (though at least one replicate per QC level) yielding IGF1 levels within 15\% of their respective nominal value (see Figures S1 and S2 in the Supplementary Material).

\subsection{Outcome Ascertainment}

All-cause mortality was the primary outcome of this study and was recorded until the end of September 2015. Up-to-date information on patient status was obtained on the basis of a continuous surveillance system of the outpatient program. In case the status of a patient was unknown, general practitioners or referring nephrologists were contacted. There was no loss to follow-up for the outcome. Specific causes of mortality were secondary outcomes of this study. This information was obtained by linking patient numbers to the database of the Dutch Central Bureau of Statistics (CBS) to retrieve causes of mortality reported by physicians. Infectious mortality was defined as mortality from infectious causes [31]. Cardiovascular mortality was defined as mortality caused by cardiovascular pathology, coded by ICD-10 codes I10-I52 [32]. Mortality due to malignancies was defined as mortality caused by malignant diseases. Miscellaneous causes of mortality were defined as other causes of death, not included in mortality from infectious causes, cardiovascular mortality, or mortality due to malignancies.

\subsection{Statistical Analyses}

Data analyses were performed using IBM SPSS Statistics for Windows (version 23.0.0.0; IBM Corp., Armonk, NY, USA) and STATA/SE (version 15.1; StataCorp, College Station, TX, USA). All p-values are two-tailed, and a p-value lower than 0.050 was considered statistically significant. Baseline characteristics are presented according to tertiles of plasma IGF1 levels for female and male RTR. Continuous data are presented as mean with SD for normally distributed variables and as median with interquartile range (IQR) for variables with skewed distributions, whereas categorical variables are presented as percentages. Differences in baseline characteristics across the tertiles were tested by one-way ANOVA, Kruskal-Wallis test, and linear-by-linear association $\chi^{2}$ test for normally distributed 
continuous, skewed continuous, and categorical variables, respectively. Multivariable linear regression was performed to assess associations between patients' characteristics and plasma IGF1 levels in female and male RTR. Models were included for analyses that were adjusted for age alone, for age and estimated glomerular filtration rate (eGFR), and for multiple variables selected following (automatic) stepwise backward elimination. The prospective associations of plasma IGF1 levels with all-cause mortality, as primary endpoint, and with cause-specific mortality, as secondary endpoint, were assessed by Cox proportional hazards regression. In order to verify the existence of effect modification by sex for the primary endpoint, we performed Cox regression analyses for the association of plasma IGF1 levels with all-cause mortality in which female and male RTR were grouped together, with additional inclusion of an interaction term of plasma IGF1 and sex in the Cox regression model. Hazard ratios (HR) and 95\% confidence intervals (CIs) were calculated per 1 unit increment in log2-transformed IGF1 levels. Thereafter, we proceeded with sex-stratified prospective analyses for all-cause mortality as a primary endpoint. In addition to crude analyses, we performed analyses with adjustment for age and eGFR with and without additional physiological, lifestyle, routine clinical chemistry, transplantation, medication, and comorbidity related variables. Subsequently, we performed mediation analyses using the method as described by Preacher and Hayes, which allowed for testing the significance and magnitude of (potential) mediation [33]. In these analyses, mediation was assessed by computing bias-corrected confidence intervals upon running 2000 bootstrap samples. The proportion of mediation was obtained by dividing the indirect effect coefficient by the total effect coefficient, which were adjusted for age and eGFR. Mediation analyses were performed using IGF1 as a potential risk factor and $24 \mathrm{~h}$ urinary creatinine excretion, a marker of muscle mass, as potential mediator while also vice versa, because the observational nature of our study does not allow for drawing conclusions on cause-effect relationships. At last, we performed Cox-regression analyses for the association of plasma IGF1 levels with cause-specific mortality as secondary endpoints. Due to lower numbers of events, the exploratory nature of these analyses, and the generally accepted rule of thumb that allows for one variable to be included for each 7-10 events in Cox regression models [34], we performed sex-stratified crude analyses Cox regression analyses and sex-stratified age- and eGFR-adjusted analyses for the separate causes of mortality.

\section{Results}

\subsection{RTR Characteristics}

Baseline characteristics according to tertiles of plasma IGF1 levels for female and male RTR are shown in Table 1. At baseline, median IGF1 levels were $153 \mathrm{ng} / \mathrm{mL}$ (IQR: 118-196) in female and 168 ng/mL (IQR: 128-224) in male RTR (see Figure 1).

Female RTR who had higher IGF1 levels were more likely to have a larger waist circumference and a higher $24 \mathrm{~h}$ urinary creatinine excretion. In turn, the prevalence of diabetes mellitus as primary renal disease, the use of insulin therapy, the cumulative prednisolone dose, and the time between transplantation and baseline measurements were lower for these subjects.

For male RTR with higher levels of IGF1, subjects were more likely to be younger, to have a higher body weight and SQUASH score, and to have a lower waist circumference, prevalence of diabetes mellitus as primary renal disease, and cumulative prednisolone dose. Male RTR in the highest tertile of IGF1 levels were furthermore more likely to have received a graft from a living donor, to have undergone dialysis before transplantation, to have a shorter time between transplantation and baseline measurements, to use calcineurin inhibitors, whereas these subjects were less likely to use coumarin derivatives. Lastly, levels of serum creatinine, plasma albumin, plasma triglycerides, and $24 \mathrm{~h}$ urinary creatinine excretion were more likely to be higher whereas plasma aspartate transaminase (AST), gamma-glutamyltransferase (GGT), and high sensitivity C-reactive protein (hs-CRP) were more likely to be lower for these subjects. 
Table 1. Baseline characteristics according to tertiles of plasma IGF1 levels in female and male RTR ${ }^{1}$.

\begin{tabular}{|c|c|c|c|c|c|c|c|c|}
\hline \multirow[b]{2}{*}{ Variable } & \multicolumn{4}{|c|}{ Tertiles of Plasma IGF1 Levels for 277 Female RTR } & \multicolumn{4}{|c|}{ Tertiles of Plasma IGF1 Levels for 343 Male RTR } \\
\hline & $<131 \mathrm{ng} / \mathrm{mL}$ & $131-181 \mathrm{ng} / \mathrm{mL}$ & $>181 \mathrm{ng} / \mathrm{mL}$ & $\begin{array}{l}p \text {-Value for } \\
\text { Trend }^{2}\end{array}$ & $<141 \mathrm{ng} / \mathrm{mL}$ & $141-202 \mathrm{ng} / \mathrm{mL}$ & $>202 \mathrm{ng} / \mathrm{mL}$ & $\begin{array}{l}p \text {-Value for } \\
\text { Trend }^{2}\end{array}$ \\
\hline Age, y & $56(48-64)$ & $54(44-63)$ & $54(41-60)$ & 0.42 & $59(48-65)$ & $55(46-61)$ & $49(38-61)$ & $<0.001$ \\
\hline BMI, kg/m² & $25(22-30)$ & $26(23-30)$ & $27(23-30)$ & 0.31 & $25(23-28)$ & $26(24-30)$ & $26(23-28)$ & 0.07 \\
\hline Body weight, $\mathrm{kg}$ & $67(61-84)$ & $73(65-81)$ & $74(65-86)$ & 0.20 & $80(73-90)$ & $86(76-97)$ & $84(74-93)$ & 0.03 \\
\hline Body length, cm & $167(161-171)$ & $167(162-173)$ & $168(163-171)$ & 0.49 & $179(174-183)$ & $180(174-184)$ & $180(174-185)$ & 0.29 \\
\hline Waist circumference, $\mathrm{cm}$ & $90(78-104)$ & $95(87-106)$ & $95(88-105)$ & 0.04 & $100(91-108)$ & $104(94-112)$ & $99(89-107)$ & 0.01 \\
\hline Blood pressure, systolic, $\mathrm{mmHg}$ & $133(121-147)$ & $131(120-142)$ & $132(124-145)$ & 0.47 & $138(127-151)$ & 135 (124-145) & $136(125-145)$ & 0.46 \\
\hline Blood pressure, diastolic, $\mathrm{mmHg}$ & $80 \pm 11$ & $80 \pm 12$ & $82 \pm 10$ & 0.15 & $83 \pm 10$ & $84 \pm 12$ & $84 \pm 10$ & 0.27 \\
\hline \multicolumn{9}{|l|}{$\begin{array}{l}\text { Lifestyle: } \\
\end{array}$} \\
\hline Smoking status, current, $\%$ & 11.6 & 8.7 & 9.0 & 0.56 & 9.8 & 17.4 & 16.4 & 0.19 \\
\hline Alcohol consumption, yes, $\%$ & 87.2 & 83.3 & 79.3 & 0.18 & 88.0 & 91.3 & 92.5 & 0.28 \\
\hline SQUASH score, $\times 1000$ & $4.9(2.6-7.6)$ & $4.3(1.7-7.1)$ & $5.0(2.0-6.7)$ & 0.60 & $5.2(1.8-7.3)$ & $6.4(3.0-10.7)$ & $5.4(2.5-9.6)$ & 0.02 \\
\hline \multicolumn{9}{|l|}{ Primary renal disease: } \\
\hline Primary glomerulosclerosis, $\%$ & 23.9 & 20.4 & 27.2 & 0.60 & 28.9 & 39.5 & 32.2 & 0.61 \\
\hline Glomerulonephritis, \% & 10.9 & 8.6 & 4.3 & 0.10 & 9.6 & 4.4 & 8.7 & 0.79 \\
\hline Polycystic kidney disease, \% & 19.6 & 24.7 & 27.2 & 0.23 & 14.0 & 19.3 & 18.3 & 0.40 \\
\hline Renal hypoplasia/dysplasia, \% & 4.3 & 5.4 & 2.2 & 0.45 & 2.6 & 3.5 & 5.2 & 0.31 \\
\hline Diabetes mellitus, $\%$ & 8.7 & 5.4 & 0.0 & 0.005 & 11.4 & 4.4 & 1.7 & 0.002 \\
\hline Other primary renal diseases, $\%$ & 32.6 & 35.5 & 39.1 & 0.36 & 32.5 & 28.9 & 33.9 & 0.81 \\
\hline \multicolumn{9}{|l|}{$\begin{array}{c}\text { Kidney and transplantation related } \\
\text { variables: }\end{array}$} \\
\hline $\mathrm{eGFR}, \mathrm{mL} / \mathrm{min}$ per $1.73 \mathrm{~m}^{2}$ & $42(27-57)$ & $45(32-57)$ & $39(25-51)$ & 0.31 & $45(32-61)$ & $43(29-55)$ & $41(31-55)$ & 0.19 \\
\hline Serum creatinine, $\mu \mathrm{mol} / \mathrm{L}$ & $110(87-148)$ & $107(87-140)$ & $118(96-162)$ & 0.23 & $128(102-167)$ & $137(115-171)$ & $148(116-175)$ & 0.04 \\
\hline Living donor, $\%$ & 28.3 & 40.2 & 39.1 & 0.13 & 26.3 & 31.9 & 42.6 & 0.009 \\
\hline Graft rejection, $\%$ & 21.7 & 22.6 & 18.5 & 0.59 & 37.7 & 32.5 & 27.0 & 0.08 \\
\hline Dialysis before transplantation, $\%$ & 87.0 & 75.3 & 78.3 & 0.14 & 91.2 & 89.5 & 79.1 & 0.007 \\
\hline $\begin{array}{l}\text { Time between transplantation and } \\
\text { baseline visit, } y\end{array}$ & $7.5(3.4-12.5)$ & $5.0(1.9-14.6)$ & $3.7(1.1-7.9)$ & 0.003 & $7.5(4.2-13.7)$ & $7.0(2.9-13.9)$ & $2.6(1.0-7.5)$ & $<0.001$ \\
\hline
\end{tabular}


Table 1. Cont.

\begin{tabular}{|c|c|c|c|c|c|c|c|c|}
\hline \multirow[b]{2}{*}{ Variable } & \multicolumn{4}{|c|}{ Tertiles of Plasma IGF1 Levels for 277 Female RTR } & \multicolumn{4}{|c|}{ Tertiles of Plasma IGF1 Levels for 343 Male RTR } \\
\hline & $<131 \mathrm{ng} / \mathrm{mL}$ & $131-181 \mathrm{ng} / \mathrm{mL}$ & $>181 \mathrm{ng} / \mathrm{mL}$ & $\begin{array}{c}p \text {-Value for } \\
\text { Trend }^{2}\end{array}$ & $<141 \mathrm{ng} / \mathrm{mL}$ & $141-202 \mathrm{ng} / \mathrm{mL}$ & $>202 \mathrm{ng} / \mathrm{mL}$ & $\begin{array}{c}p \text {-Value for } \\
\text { Trend }^{2}\end{array}$ \\
\hline \multicolumn{9}{|l|}{ Blood markers: } \\
\hline ALT, U/L & $18(13-25)$ & $18(13-22)$ & $18(13-23)$ & 0.81 & $21(16-29)$ & $20(16-27)$ & $19(14-27)$ & 0.32 \\
\hline AST, U/L & $23(18-29)$ & $22(18-26)$ & $20(18-25)$ & 0.08 & $24(20-31)$ & $22(19-26)$ & $21(17-25)$ & $<0.001$ \\
\hline GGT, U/L & $29(19-49)$ & $25(16-37)$ & $25(18-34)$ & 0.09 & $32(21-48)$ & $27(19-43)$ & $24(18-33)$ & 0.004 \\
\hline Albumin, g/L & $42(40-45)$ & $42(41-45)$ & $43(42-45)$ & 0.10 & $42(41-45)$ & $43(41-44)$ & $44(42-45)$ & 0.003 \\
\hline Glucose, $\mathrm{mmol} / \mathrm{L}$ & $5.0(4.6-6.2)$ & $5.2(4.7-5.9)$ & $5.2(4.7-5.6)$ & 0.66 & $5.4(4.9-6.2)$ & $5.3(4.9-6.2)$ & $5.3(5.0-5.9)$ & 0.86 \\
\hline $\mathrm{HbA} 1 \mathrm{c}, \%$ & $5.7(5.4-6.0)$ & $5.9(5.5-6.3)$ & $5.9(5.5-6.3)$ & 0.39 & $5.8(5.5-6.2)$ & $5.8(5.5-6.3)$ & $5.8(5.5-6.2)$ & 0.68 \\
\hline Triglycerides, mmol/L & $1.7(1.2-2.6)$ & $1.7(1.3-2.1)$ & $1.7(1.3-2.3)$ & 0.97 & $1.6(1.1-2.2)$ & $1.7(1.2-2.9)$ & $1.8(1.4-2.3)$ & 0.03 \\
\hline Total cholesterol, mmol/L & $5.5(4.6-6.4)$ & $5.1(4.4-6.1)$ & $5.2(4.6-5.9)$ & 0.32 & $5.1(4.3-5.9)$ & $4.8(4.2-5.6)$ & $4.8(4.3-5.6)$ & 0.29 \\
\hline $\mathrm{HDL}$ cholesterol, mmol/L & $1.6(1.1-1.9)$ & $1.4(1.2-1.8)$ & $1.4(1.2-1.8)$ & 0.22 & $1.3(1.1-1.6)$ & $1.2(0.9-1.4)$ & $1.2(1.0-1.4)$ & 0.05 \\
\hline LDL cholesterol, mmol/L & $3.0(2.3-3.7)$ & $3.0(2.2-3.9)$ & $3.0(2.5-3.5)$ & 0.94 & $2.9(2.3-3.7)$ & $2.8(2.3-3.5)$ & $2.8(2.3-3.5)$ & 0.43 \\
\hline hs-CRP, mg/L & $1.8(0.9-5.2)$ & $2.0(0.9-5.4)$ & $1.7(0.8-3.0)$ & 0.23 & $1.8(0.8-5.5)$ & $1.9(0.8-5.1)$ & $1.3(0.5-3.4)$ & 0.03 \\
\hline Follicle-stimulating hormone, $\mathrm{U} / \mathrm{L}$ & $52(7-90)$ & $51(5-81)$ & $47(5-78)$ & 0.87 & $5.2(3.0-11.0)$ & $5.7(3.8-10.7)$ & $4.9(2.9-8.3)$ & 0.20 \\
\hline $\begin{array}{c}\text { Follicle-stimulating hormone } \\
\geq 34 \mathrm{U} / \mathrm{L} \text {, yes, } \%^{3}\end{array}$ & 64.0 & 65.2 & 63.6 & 0.95 & 3.8 & 5.8 & 1.8 & 0.43 \\
\hline Luteinizing hormone, $\mathrm{U} / \mathrm{L}$ & $32(8-55)$ & $28(6-56)$ & $32(8-58)$ & 0.95 & $5.0(3.4-8.3)$ & $5.1(3.6-8.5)$ & $5.1(3.4-6.9)$ & 0.52 \\
\hline \multicolumn{9}{|l|}{ Urine markers: } \\
\hline $\begin{array}{l}\text { Urinary creatinine excretion, } \\
\mathrm{mmol} / 24 \mathrm{~h}\end{array}$ & $8.6(7.3-10.1)$ & $9.6(8.0-11.3)$ & $10.1(9.0-11.3)$ & $<0.001$ & $12.3(10.3-14.5)$ & $13.1(11.0-15.4)$ & $13.6(11.4-15.7)$ & 0.008 \\
\hline Urine total protein, $\mathrm{g} / 24 \mathrm{~h}$ & $0.14(0.02-0.47)$ & $0.15(0.02-0.29)$ & $0.15(0.02-0.29)$ & 0.67 & $0.24(0.02-0.52)$ & $0.25(0.02-0.59)$ & $0.21(0.02-0.34)$ & 0.29 \\
\hline \multicolumn{9}{|l|}{ Medication use: } \\
\hline Proliferation inhibitors, yes, $\%$ & 81.5 & 84.9 & 83.7 & 0.69 & 79.8 & 86.8 & 80.0 & 0.98 \\
\hline Coumarin derivatives, yes, $\%$ & 14.1 & 9.7 & 7.6 & 0.15 & 16.7 & 11.4 & 7.8 & 0.04 \\
\hline Calcineurin inhibitors, yes, $\%$ & 54.3 & 51.6 & 66.3 & 0.10 & 48.2 & 55.3 & 80.0 & $<0.001$ \\
\hline Sirolimus, yes, $\%$ & 1.2 & 4.5 & 0.0 & 0.55 & 4.6 & 0.9 & 1.0 & 0.07 \\
\hline Antihypertensive drugs, yes, $\%$ & 87.0 & 81.7 & 89.1 & 0.67 & 88.6 & 92.1 & 91.3 & 0.48 \\
\hline Statins, yes, $\%$ & 48.9 & 55.9 & 51.1 & 0.57 & 53.1 & 60.5 & 43.5 & 0.14 \\
\hline Diabetes, yes, \% & 28.3 & 23.7 & 26.1 & 0.74 & 27.2 & 22.8 & 20.0 & 0.20 \\
\hline Antidiabetics, yes, $\%$ & 21.7 & 15.1 & 13.0 & 0.11 & 17.5 & 15.8 & 12.2 & 0.26 \\
\hline Metformin, yes, \% & 3.3 & 4.3 & 4.3 & 0.71 & 7.9 & 2.6 & 3.5 & 0.11 \\
\hline Insulin therapy, yes, $\%$ & 17.4 & 10.8 & 7.6 & 0.04 & 10.5 & 7.9 & 6.1 & 0.22 \\
\hline Prednisolone, yes, $\%$ & 97.8 & 98.9 & 98.9 & 0.54 & 100.0 & 97.4 & 100.0 & 1.00 \\
\hline Prednisolone, cumulative dose, $\mathrm{g}^{4}$ & $23(10-37)$ & $19(6-40)$ & $11(4-25)$ & 0.01 & $23(14-42)$ & $23(10-46)$ & $10(4-28)$ & $<0.001$ \\
\hline
\end{tabular}

${ }^{1}$ Continuous variables are reported as 'mean \pm standard deviation' when normally distributed (Shapiro-Wilk test $p \geq 0.05$ ) or 'median (interquartile range)' when not normally distributed (Shapiro-Wilk test $p<0.05$ ), and categorical variables are reported as percentage. ${ }^{2}$ Determined by linear-by-linear association $\chi^{2}$ test (categorical variables), Kruskal-Wallis test (continuous variables, not normally distributed), or one-way ANOVA (continuous variables, normally distributed). ${ }^{3} \mathrm{~A}$ follicle-stimulating hormone cut-off level of $\geq 34 \mathrm{U} / \mathrm{L}$ was used to derive a surrogate marker of post-menopause [35]. Abbreviations: ALT: Alanine transaminase; AST: Aspartate transaminase; BMI: Body mass index; eGFR: Estimated glomerular filtration rate; GGT: Gamma-glutamyltransferase; HbA1c: Glycated hemoglobin; HDL: High-density lipoprotein; hs-CRP: High sensitivity C-reactive protein; LDL: Low-density lipoprotein; SQUASH: Short QUestionnaire to ASsess Health-enhancing physical activity [27]. ${ }^{4}$ The cumulative dose of prednisolone was calculated as the sum of the maintenance dose of prednisolone until inclusion and the dose of prednisolone or methylprednisolone required for treatment of acute rejection (a conversion factor of 1.25 was used to convert methylprednisolone dose to its prednisolone dose equivalent). 


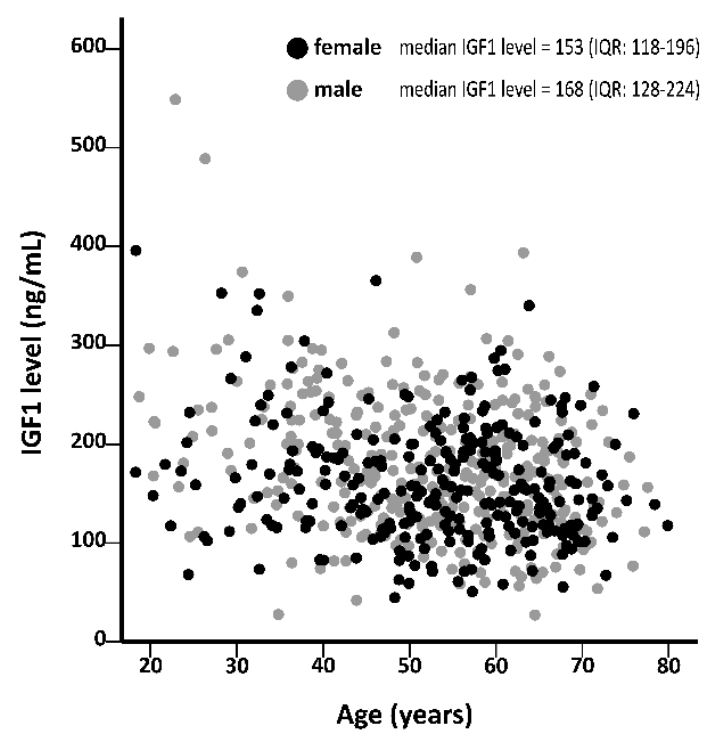

Figure 1. Association between insulin-like growth factor 1 (IGF1) levels and age for female and male renal transplant recipients (RTR).

\subsection{Association of Plasma IGF1 with Selected Variables in RTR}

Associations between plasma IGF1 levels and variables of interest adjusted for age alone, for age and eGFR, and for multiple variables which were selected following stepwise backward elimination are shown in Table 2.

For female RTR, the analyses adjusted for age featured positive and significant associations between plasma IGF1 and body weight, $24 \mathrm{~h}$ urinary creatinine excretion, and calcineurin inhibitor use. Significant inverse associations with plasma IGF1, independent of age, were observed for the prevalence of diabetes mellitus as primary renal disease, the time between transplantation and baseline measurements, the cumulative prednisolone dose, and GGT. After further adjustment for eGFR, the magnitude, direction, and significance of all associations generally remained the same. The final stepwise backward model featured an adjusted $\mathrm{R}^{2}$ of 0.14 and revealed significant positive associations between plasma IGF1 and both $24 \mathrm{~h}$ urinary creatinine excretion and calcineurin inhibitor use, but also significant inverse associations with the prevalence of diabetes mellitus as primary renal disease, GGT, HDL cholesterol, and hs-CRP.

For male RTR, analyses adjusted for age showed significant positive associations between plasma IGF1 and both albumin and calcineurin inhibitor use. Significant inverse associations were observed between plasma IGF1 and eGFR, the prevalence of diabetes mellitus as primary renal disease, the cumulative prednisolone dose, AST, and GGT, and the time between transplantation and baseline measurements. Further adjustment for eGFR did not lead to major changes in the magnitude, direction, or significance of these associations. Lastly, an adjusted $R^{2}$ of 0.28 was obtained for the final stepwise backward model which featured significant positive associations between plasma IGF1 and both albumin and calcineurin inhibitor use. Significant inverse associations were furthermore revealed between plasma IGF1 and age, eGFR, the prevalence of diabetes mellitus as primary renal disease, and GGT. 
Table 2. Multivariable linear regression analysis with plasma IGF1 as the dependent variable in female and male RTR ${ }^{1}$.

\begin{tabular}{|c|c|c|c|c|c|c|c|c|c|c|c|c|}
\hline \multirow[b]{3}{*}{ Variable } & \multicolumn{6}{|c|}{ Female RTR $(N=277)$} & \multicolumn{6}{|c|}{ Male RTR $(\mathrm{N}=343)$} \\
\hline & \multicolumn{2}{|c|}{ Age Adjusted } & \multicolumn{2}{|c|}{$\begin{array}{l}\text { Age and eGFR } \\
\text { Adjusted }\end{array}$} & \multicolumn{2}{|c|}{$\begin{array}{c}\text { Backward } \\
\left.\text { (adj. } R^{2}=0.14\right)\end{array}$} & \multicolumn{2}{|c|}{ Age Adjusted } & \multicolumn{2}{|c|}{$\begin{array}{c}\text { Age and eGFR } \\
\text { Adjusted }\end{array}$} & \multicolumn{2}{|c|}{$\begin{array}{c}\text { Backward } \\
\left.\text { (adj. } R^{2}=0.28\right)\end{array}$} \\
\hline & Stand. $\beta$ & $p$-Value & Stand. $\beta$ & $p$-Value & Stand. $\beta$ & $p$-Value & Stand. $\beta$ & $p$-Value & Stand. $\beta$ & $p$-Value & Stand. $\beta$ & $p$-Value \\
\hline Age, $y$ & -0.16 & 0.007 & -0.17 & 0.006 & & & -0.32 & $<0.001$ & -0.35 & $<0.001$ & -0.27 & $<0.001$ \\
\hline eGFR, $\mathrm{mL} / \mathrm{min}$ per $1.73 \mathrm{~m}^{2}$ & -0.05 & 0.37 & -0.05 & 0.37 & & & -0.18 & 0.001 & -0.18 & 0.001 & -0.19 & 0.001 \\
\hline Body weight, kg & 0.12 & 0.05 & 0.11 & 0.06 & & & 0.01 & 0.87 & -0.01 & 0.88 & & \\
\hline Body length, $\mathrm{cm}$ & 0.09 & 0.14 & 0.09 & 0.14 & & & 0.00 & 0.97 & -0.02 & 0.74 & & \\
\hline SQUASH score & -0.05 & 0.43 & -0.04 & 0.49 & -0.11 & 0.09 & 0.02 & 0.64 & 0.05 & 0.38 & & \\
\hline Diabetes mellitus, yes vs. no & -0.13 & 0.04 & -0.13 & 0.03 & -0.13 & 0.04 & -0.12 & 0.02 & -0.14 & 0.008 & -0.13 & 0.009 \\
\hline Living donor, yes vs. no & 0.02 & 0.71 & 0.03 & 0.63 & & & 0.02 & 0.66 & 0.04 & 0.44 & & \\
\hline Graft rejection, yes vs. no & -0.05 & 0.37 & -0.07 & 0.28 & & & -0.10 & 0.06 & -0.10 & 0.05 & -0.09 & 0.06 \\
\hline Dialysis before transplantation, yes vs. no & 0.07 & 0.28 & 0.07 & 0.23 & & & 0.05 & 0.39 & 0.06 & 0.26 & & \\
\hline $\begin{array}{l}\text { Time between transplantation and } \\
\text { baseline visit, y }\end{array}$ & -0.14 & 0.02 & -0.14 & 0.02 & & & -0.15 & 0.003 & -0.15 & 0.004 & & \\
\hline $\mathrm{AST}, \mathrm{U} / \mathrm{L}$ & -0.09 & 0.16 & -0.09 & 0.16 & & & -0.21 & $<0.001$ & -0.15 & 0.005 & -0.10 & 0.06 \\
\hline GGT, U/L & -0.12 & 0.04 & -0.13 & 0.03 & -0.14 & 0.02 & -0.22 & $<0.001$ & -0.20 & $<0.001$ & -0.18 & 0.001 \\
\hline Albumin, g/L & 0.09 & 0.15 & 0.10 & 0.11 & & & 0.12 & 0.03 & 0.17 & 0.003 & 0.15 & 0.01 \\
\hline Triglycerides, mmol/L & -0.06 & 0.36 & -0.07 & 0.23 & -0.11 & 0.10 & 0.09 & 0.08 & 0.06 & 0.26 & & \\
\hline $\mathrm{HDL}$ cholesterol, $\mathrm{mmol} / \mathrm{L}$ & -0.08 & 0.20 & -0.07 & 0.27 & -0.14 & 0.03 & -0.09 & 0.08 & -0.05 & 0.32 & & \\
\hline hs-CRP, mg/L & -0.10 & 0.09 & -0.10 & 0.09 & -0.15 & 0.01 & -0.04 & 0.49 & -0.06 & 0.22 & & \\
\hline Urinary creatinine excretion, $\mathrm{mmol} / 24 \mathrm{~h}$ & 0.24 & $<0.001$ & 0.25 & $<0.001$ & 0.25 & $<0.001$ & 0.07 & 0.19 & 0.06 & 0.22 & & \\
\hline Coumarin derivatives, yes vs. no & -0.09 & 0.13 & -0.10 & 0.11 & & & -0.02 & 0.67 & -0.05 & 0.34 & & \\
\hline Calcineurin inhibitors, yes vs. no & 0.15 & 0.01 & 0.15 & 0.02 & 0.16 & 0.01 & 0.20 & $<0.001$ & 0.16 & 0.003 & 0.18 & 0.001 \\
\hline Sirolimus, yes vs. no & -0.07 & 0.23 & -0.07 & 0.23 & & & -0.06 & 0.24 & -0.05 & 0.30 & & \\
\hline Insulin therapy, yes vs. no & -0.10 & 0.10 & -0.11 & 0.08 & & & -0.06 & 0.26 & -0.07 & 0.19 & & \\
\hline Prednisolone, cumulative dose, $\mathrm{g}^{2}$ & -0.12 & 0.05 & -0.12 & 0.05 & & & -0.13 & 0.01 & -0.13 & 0.01 & & \\
\hline
\end{tabular}

${ }^{1}$ Variables showing $p$-values below 0.10 for the trend of tertiles of IGF1 in at least one of the sexes (see Table 1), with the exception of highly correlated variables (e.g., BMI, waist circumference, serum creatinine), as well as body weight and body height were included for multivariable linear regression analysis. Abbreviations: AST: Aspartate transaminase; eGFR Estimated glomerular filtration rate; GGT: Gamma-glutamyltransferase; HDL: High-density lipoprotein; hs-CRP: High sensitivity C-reactive protein; SQUASH: Short QUestionnaire to ASsess Health-enhancing physical activity [27]. ${ }^{2}$ The cumulative dose of prednisolone was calculated as the sum of the maintenance dose of prednisolone dose of prednisolone or methylprednisolone required for treatment of acute rejection (a conversion factor of 1.25 was used to convert the methylprednisolone dose to its prednisolone dose equivalent). 


\subsection{Association of Plasma IGF1 with All-Cause Mortality in RTR}

Median follow-up was 5.4 years (IQR: 4.8-6.0 years) for female and 5.4 years (IQR: 4.8-6.3 years) for male RTR. During this prospective follow-up, 56 female and 77 male RTR died. We first investigated whether the association of plasma IGF1 levels with all-cause mortality was modified by sex. In these analyses, with data of female and male RTR combined, we found that higher plasma IGF1 levels were associated with a significantly decreased risk (HR per $\log 2$ increment of plasma IGF1, 95\% CI) of all-cause mortality $(0.61,0.47-0.80 ; p<0.001)$. Furthermore, inclusion of a product-term of (log2-transformed plasma) IGF1 levels and sex in the basic multivariable model (i.e., with adjustment for age and eGFR) revealed the existence of significant effect modification by sex ( $p$ for interaction $=0.02$ ). After finding this significant interaction by sex, we proceeded with sex-stratified analyses of the association of (log2-transformed) plasma IGF1 levels with all-cause mortality. For female RTR, the crude analyses showed that higher plasma IGF1 levels were associated with a significantly decreased risk of all-cause mortality $(0.42,0.26-0.66 ; p<0.001$; see Figure 2 and Table 3$)$, while a nonsignificant trend towards a decreased risk was observed for male RTR $(0.74,0.52-1.04 ; p=0.09$; see Table 3 and Figure 2).

\section{7 female RTRs}

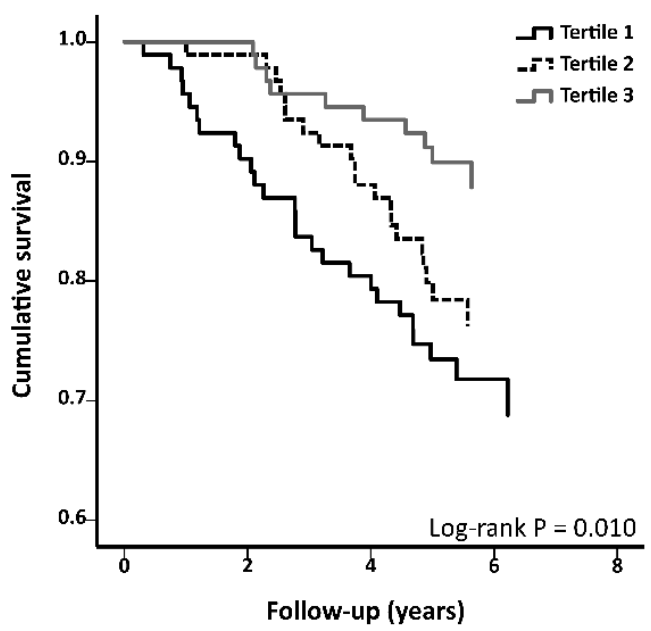

(a)
343 male RTRs

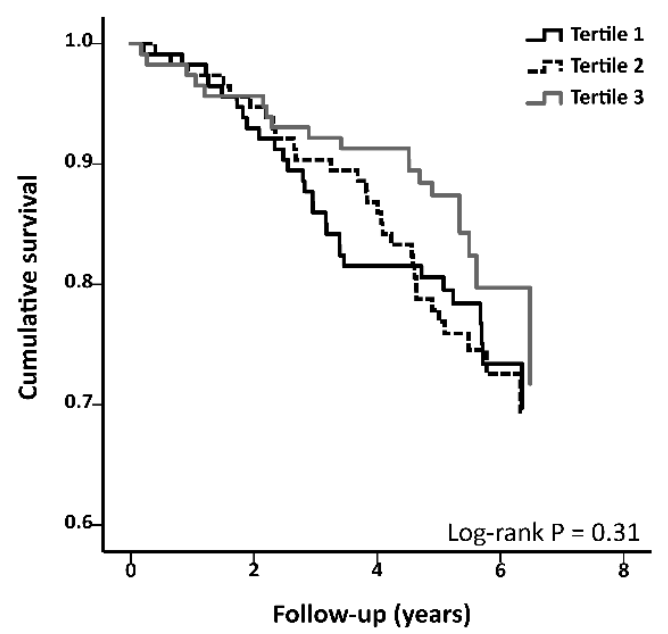

(b)

Figure 2. Kaplan-Meier curves for all-cause mortality according to tertiles of plasma insulin-like growth factor 1 (IGF1) in (a) female and (b) male renal transplant recipients (RTR). For female RTR, IGF1 levels of the tertiles 1, 2, and 3 are below $131 \mathrm{ng} / \mathrm{mL}$, range between 131 and $181 \mathrm{ng} / \mathrm{mL}$, and are above $181 \mathrm{ng} / \mathrm{mL}$, respectively. For male RTR, IGF1 levels of the tertiles 1, 2, and 3 are below $141 \mathrm{ng} / \mathrm{mL}$, range between 141 and 202 ng/mL, and are above 202 ng/mL, respectively.

In the model with adjustment for age and eGFR, the significant inverse association of IGF1 with all-cause mortality remained in female RTR $(0.40,0.24-0.65 ; p<0.001)$ and the association in male RTR remained insignificant $(0.85,0.56-1.29 ; p=0.44)$. Further adjustment for potential confounders, which was assessed based on seven different multivariable models, did not substantially affect the associations between plasma IGF1 and mortality for both female and male subjects (see Table 3). Lastly, mediation analysis (according to the procedures of Preacher and Hayes [33]) was carried out for the female subjects and revealed $24 \mathrm{~h}$ urinary creatinine excretion as significant mediator ( $p$-value for indirect effect $<0.05$ ) accounting for $39 \%$ on the association between plasma IGF1 and all-cause mortality (see Table 4). Since the observational nature of our study does not allow for drawing conclusions regarding cause-effect relationships, we also performed alternative mediation analyses with $24 \mathrm{~h}$ urinary creatinine excretion as potential risk factors and plasma IGF1 levels as potential mediators. In these analyses, we found that plasma IGF1 levels as significant mediators ( $p$-value for indirect effect 
$<0.05$ ) accounted for $9 \%$ on the association between $24 \mathrm{~h}$ urinary creatinine excretion and all-cause mortality (see Supplemental Table S5).

Table 3. Association between log2-transformed plasma IGF1 levels and the risk of all-cause mortality in female and male RTR ${ }^{1}$.

\begin{tabular}{ccccccc}
\hline & \multicolumn{2}{c}{ 277 Female RTR (56 Events) } & \multicolumn{2}{c}{ 343 Male RTR (77 Events) } \\
\hline Variable & HR (log2) & 95\% CI & $p$-Value & HR (log2) & 95\% CI & $p$-Value \\
\hline Crude model & 0.42 & $0.26-0.66$ & $<0.001$ & 0.74 & $0.52-1.04$ & 0.09 \\
Model 1 2 & 0.40 & $0.24-0.65$ & $<0.001$ & 0.85 & $0.56-1.29$ & 0.44 \\
Model 2 $^{3}$ & 0.47 & $0.27-0.81$ & 0.006 & 0.88 & $0.58-1.34$ & 0.55 \\
Model 3 $^{4}$ & 0.33 & $0.16-0.64$ & 0.001 & 0.88 & $0.54-1.42$ & 0.60 \\
Model 4 $^{5}$ & 0.38 & $0.23-0.63$ & $<0.001$ & 0.81 & $0.51-1.27$ & 0.35 \\
Model 5 & 0.39 & $0.24-0.65$ & $<0.001$ & 0.87 & $0.57-1.32$ & 0.50 \\
Model 6 $^{7}$ & 0.34 & $0.20-0.57$ & $<0.001$ & 0.94 & $0.61-1.45$ & 0.78 \\
Model 7 & 0.36 & $0.21-0.61$ & $<0.001$ & 1.06 & $0.66-1.69$ & 0.82 \\
Model 8 & 0.41 & $0.24-0.69$ & 0.001 & 0.85 & $0.55-1.29$ & 0.44 \\
\hline
\end{tabular}

${ }^{1}$ Hazard ratios (HR) per 1 unit increment in log2-transformed plasma IGF1 levels and corresponding $95 \%$ confidence intervals (CI) were derived from Cox proportional hazards models. ${ }^{2}$ Multivariable model adjusted for age and estimated glomerular filtration rate (eGFR). ${ }^{3}$ Multivariable model adjusted for age, eGFR, body length, body weight, waist circumference, systolic blood pressure, and diastolic blood pressure. ${ }^{4}$ Multivariable model adjusted for age, eGFR, smoking status, alcohol consumption, and Short QUestionnaire to ASsess Health-enhancing physical activity (SQUASH) score [27]. ${ }^{5}$ Multivariable model adjusted for age, eGFR, glucose, glycated hemoglobin (HbA1c), triglycerides, serum total cholesterol, high-density lipoprotein (HDL) cholesterol, and low-density lipoprotein (LDL) cholesterol. ${ }^{6}$ Multivariable model adjusted for age, eGFR, serum creatinine, and urine total protein. ${ }^{7}$ Multivariable model adjusted for age, eGFR, primary renal disease, graft rejection, dialysis before transplantation, time between transplantation and baseline visit, and donor status. ${ }^{8}$ Multivariable model adjusted for age, eGFR, aspartate transaminase (AST), gamma-glutamyltransferase (GGT), serum albumin, high sensitivity C-reactive protein (hs-CRP), follicle-stimulating hormone, and luteinizing hormone. ${ }^{9}$ Multivariable model adjusted for age, eGFR, antidiabetics, antihypertensive drugs, coumarin derivatives, proliferation inhibitors, calcineurin inhibitors, insulin, and prednisolone.

Table 4. Mediation analysis of the relationship between plasma IGF1, $24 \mathrm{~h}$ urinary creatinine excretion, and all-cause mortality in female RTR.

\begin{tabular}{|c|c|c|c|}
\hline \multirow[b]{2}{*}{ Potential Mediator } & \multirow[b]{2}{*}{ Effect $^{2}$} & \multicolumn{2}{|c|}{ Multivariable Model $^{1}$} \\
\hline & & Coefficient $(95 \% \mathrm{CI}, b c)^{3}$ & Proportion Mediated $^{4}$ \\
\hline $\begin{array}{l}24 \mathrm{~h} \text { urinary creatinine } \\
\text { excretion }\end{array}$ & $\begin{array}{l}\text { indirect effect ( } a b \text { path) } \\
\text { direct effect (c' path) } \\
\text { total effect }\left(a b+c^{\prime} \text { path) }\right.\end{array}$ & $\begin{array}{l}-0.11(-0.18--0.06) \\
-0.17(-0.33--0.02) \\
-0.28(-0.44--0.12)\end{array}$ & $39.3 \%$ \\
\hline
\end{tabular}

\footnotetext{
${ }^{1}$ Coefficients and corresponding $95 \%$ confidence intervals (CI) of the indirect and total effects are standardized for the standard deviations of the potential mediator, plasma IGF1, and all-cause mortality. ${ }^{2}$ Coefficients are adjusted for age and estimated glomerular filtration rate (eGFR). ${ }^{3} 95 \%$ CIs for the indirect and total effects are bias-corrected confidence intervals after running 2000 bootstrap samples. ${ }^{4}$ The size of (statistically significant) mediated effects is calculated by dividing the standardized indirect effect by the standardized total effect followed by multiplication by 100 .
}

\subsection{Association of Plasma IGF1 with Cause-Specific Mortality in RTR}

Next, we performed sex-stratified analyses of the association of log2-transformed plasma IGF1 levels with mortality from specific causes of death, namely death from infectious diseases, cardiovascular mortality, death from malignancies, and other, miscellaneous causes of death. In females, we found that higher plasma IGF1 levels were strongly associated with a significantly decreased risk of infectious disease-related mortality $(0.17,0.07-0.38 ; p<0.001$; see Supplemental Table S1, Model 1$)$. In females, we also found a borderline significant association of higher plasma IGF1 levels with cardiovascular mortality $(0.43,0.18-1.00 ; p=0.05$; see Supplemental Table S2, Model 1), but neither a significant association with cancer-related mortality $(1.50,0.45-4.93 ; p=0.51$; see Supplemental Table S3, Model $1)$, nor with mortality from miscellaneous causes $(0.43,0.10-1.78 ; p=0.24$; see Supplemental Table 
S4, Model 1). In males, no significant associations with cause-specific mortality were encountered (see respective Supplemental Tables S1-S4).

\section{Discussion}

This study showed that low plasma IGF1 levels were independently associated with an increased risk of all-cause mortality in female RTR. Such association was less pronounced and insignificant in male RTR, which should be seen in the context of IGF1 levels being negatively and strongly associated with age in males, which may explain why low plasma IGF1 levels were not associated with mortality in males. Adjustment for potential confounders did not alter the association observed in women, and $39 \%$ of this association was found to be mediated by $24 \mathrm{~h}$ urinary creatinine excretion, a marker of muscle mass. In alternative analyses, we found that $9 \%$ of the association of urinary creatinine excretion with mortality in women was mediated by plasma IGF1 levels. In secondary analyses, in which the association of plasma IGF1 with cause-specific mortality was assessed, we found a particularly strong association of low plasma IGF1 levels with increased risk of mortality due to infectious causes in females.

To our knowledge, this is the first study that investigated the association between IGF1 and long-term outcomes in RTR, hence we were limited in comparing our study with existing literature. Studies addressing associations between IGF1 and outcomes in other clinical settings are available, yet such studies are scarce and generally do not assess female and male subjects separately. When attempting to compare our results to studies on IGF1 in which both sexes were analyzed separately, we found inconsistent evidence. For example, in a cross-sectional study of 5388 US adults, the magnitude of the (positive) association between high IGF1 levels and the risk of chronic kidney disease was found to be stronger for males than for females [36]. In addition, a study of 183 healthy nonagenarians (i.e., people between the age of 90 and 99) reported a significant association between low IGF1 levels and longer survival in female subjects which was not observed for males [11]. Recently, a prospective population-based study on 1618 elderly adults reported that men featured greater decreases in IGF1 and its most important binding protein (i.e., IGF binding protein 3) with age as compared to females [37]. A recently described cross-sectional study on 200 elderly subjects furthermore reported a (negative) association between IGF1 levels and co-existent frailty and low muscle mass in female subjects whereas such association was not found for male subjects [38]. The difference between females and males as we observed in our study therefore links to previous data but also connects to why gender-specific reference ranges for IGF1 are being employed in routine clinical practice [39-41]. It should, however, be noted that all these results were obtained using different analytical methods, and it is known that different methods may yield different analyte levels, particularly in the case of IGF1 [42,43]. Moreover, IGF1 predominantly circulates being bound to IGF binding proteins [44], and the efficiency of dissociating such complexes may vary between (immuno)assays from different vendors and thereby lead to biased, or at least to incomparable results [45].

With respect to the observed association between IGF1 and mortality in female RTR, several other findings which were put forward in our study should be taken into consideration. Firstly, the identification of $24 \mathrm{~h}$ urinary creatinine excretion as a strong mediator in this association represents an interesting finding of our study. The fact that $24 \mathrm{~h}$ urinary creatinine is a widely available and accepted marker reflecting muscle mass [46-48] and the recognition of IGF1 as a growth hormone involved in muscle growth $[49,50]$ support the biological plausibility of a link between IGF1 and physical fitness. Low physical activity is, in fact, known to be a risk factor for morbidity and mortality in RTR [51-53], hence further studies on IGF1 in this context are warranted. Secondly, the significant association between IGF1 and the use of calcineurin inhibitors should be viewed in this context as well. The target of these drugs, calcineurin, has been described as a regulator of muscle mass, although it should be noted that much is still unknown about the underlying mechanisms [54-56]. Thirdly, the observed strongly significant association of higher plasma IGF1 levels with lower risk for infectious disease-related mortality may be interesting as well in this regard. At last, it should be noted that 
evidence for a potential link between IGF1 and physical fitness is currently still circumstantial and that further research is needed to verify and explore our findings.

Important limitations of this study include the facts that it represents a single-center study and that it addresses a population consisting mainly of Caucasian participants. It is unknown whether our findings can be extrapolated to other populations, and repeating this study in other populations is therefore desirable. Moreover, there may be untested or residual confounding relevant for the observed association, as is often true for observational studies. Moreover, laboratory markers were analyzed only once at baseline, hence corresponding changes over time could not be addressed in the present study. With respect to the IGF1 measurements, it should be noted that measurements were carried out using biobanked samples which had been stored for several years at $-80{ }^{\circ} \mathrm{C}$. Sample stability parameters (e.g., freeze-thaw stability, benchtop stability) were addressed during validation of our IGF1 method thereby following the US Food and Drug Administration (FDA) guidelines on bioanalytical method validation [30]. Nonetheless, storage conditions comparable to those applying to the long-term stored plasma samples could not possibly be addressed during validation, as is often the case when targeting biobanked samples. We could, however, monitor the extent of IGF1 oxidation which represents a prominent feature of our mass spectrometric IGF1 assay [29] considering that protein oxidation is a (unwanted) chemical modification occurring during storage of proteins [57]; yet, no abnormalities in IGF1 oxidation were observed. In order to reduce the (potential) impact of corresponding pre-analytical variability on the quality of our data, we only included samples which had not undergone any previous freeze-thaw cycle and we verified that the samples had not been exposed to deviating storage conditions, for example caused by power outages or freezer malfunctions.

Strengths of this study are its prospective design, the relatively large cohort of well-characterized, stable RTR, the complete follow-up for all-cause mortality, the availability of detailed data on potential confounders, and the use of a mass spectrometric IGF1 assay which allowed for highly selective IGF1 quantification.

In conclusion, low plasma IGF1 levels were found to be associated with an increased risk of all-cause mortality in female RTR, and this association was not found (to be significant) for male RTR. The association in females was mediated for a substantial proportion by $24 \mathrm{~h}$ urinary creatinine excretion which hints at a possible link with conditions of low muscle mass (e.g., poor physical fitness, poor nutritional state). Secondary analyses pointed towards a particularly strong association of low plasma IGF1 levels with mortality from infectious causes. Further research is, however, needed to explore the existence and/or relevance of such a link, and also to investigate whether IGF1 can be useful as a (predictive) marker of mortality in female RTR possibly by reflecting physical fitness in this population.

Supplementary Materials: The following are available online at http://www.mdpi.com/2077-0383/9/2/293/s1. Figure S1: Overview of calibration data for the thirteen runs carried out for quantification of insulin-like growth factor 1 (IGF1) in the clinical samples. Figure S2: Overview of the quality control data obtained during the thirteen runs carried out for quantification of insulin-like growth factor 1 (IGF1) in the clinical samples. Table S1: Association between log2-transformed plasma IGF1 levels and the risk of infectious disease-related mortality in female and male RTR. Table S2: Association between log2-transformed plasma IGF1 levels and the risk of cardiovascular mortality in female and male RTR. Table S3: Association between log2-transformed plasma IGF1 levels and the risk of cancer-related mortality in female and male RTR. Table S4: Association between log2-transformed plasma IGF1 levels and the risk of miscellaneous-cause mortality in female and male RTR. Table S5: Mediation analysis of the relationship between $24 \mathrm{~h}$ urinary creatinine excretion, plasma IGF1 levels, and all-cause mortality in female RTR.

Author Contributions: F.K., N.H.T.t.H., P.H., R.B., and S.J.L.B.; Methodology, F.K., L.M.K., A.W.G.-N., S.P.S., N.H.T.t.H., I.P.K., A.P.v.B., E.v.d.B., P.H., R.B., and S.J.L.B.; Formal analysis, F.K., L.M.K., P.H., and S.J.L.B.; Data curation, F.K., L.M.K., A.W.G.-N., S.P.S., E.v.d.B., and S.J.L.B.; Writing-original draft preparation, F.K., L.M.K., R.B., and S.J.L.B.; Writing — review and editing, F.K., L.M.K., A.W.G.-N., S.P.S., N.H.T.t.H., I.P.K., A.P.v.B., E.v.d.B., P.H., R.B., and S.J.L.B.; Supervision, R.B. and S.J.L.B.; Funding acquisition, N.H.T.t.H., R.B., and S.J.L.B. All authors have read and agreed to the published version of the manuscript. 
Funding: This research was funded by the Netherlands Organisation for Scientific Research NWO domain Applied and Engineering Sciences (Perspectief program P12-04, project 13541) and the Top Institute Food and Nutrition (program A-1003).

Acknowledgments: The authors gratefully acknowledge the Dutch Biomarker Development Center (BDC; http: //www.biomarkerdevelopmentcenter.nl/) for support of this work.

Conflicts of Interest: The authors declare no conflict of interest.

\section{References}

1. Sowers, M.R.; Zheng, H.; McConnell, D.; Nan, B.; Harlow, S.; Randolph, J.F., Jr. Follicle stimulating hormone and its rate of change in defining menopause transition stages. J. Clin. Endocrinol. Metab. 2008, 93, 3958-3964. [CrossRef] [PubMed]

2. Ketha, H.; Singh, R.J. Clinical assays for quantitation of insulin-like-growth-factor-1 (IGF1). Methods 2015, 81, 93-98. [CrossRef] [PubMed]

3. Laron, Z. Insulin-like growth factor 1 (IGF-1): A growth hormone. Mol. Pathol. 2001, 54, 311-316. [CrossRef]

4. Bidlingmaier, M. Pitfalls of insulin-like growth factor I assays. Horm. Res. 2009, 71 (Suppl. S1), 30-33. [CrossRef]

5. Mao, K.; Quipildor, G.F.; Tabrizian, T.; Novaj, A.; Guan, F.; Walters, R.O.; Delahaye, F.; Hubbard, G.B.; Ikeno, Y.; Ejima, K.; et al. Late-Life targeting of the IGF-1 receptor improves healthspan and lifespan in female mice. Nat. Commun. 2018, 9, 2394. [CrossRef]

6. Holzenberger, M.; Dupont, J.; Ducos, B.; Leneuve, P.; Geloen, A.; Even, P.C.; Cervera, P.; Le Bouc, Y. IGF-1 receptor regulates lifespan and resistance to oxidative stress in mice. Nature 2003, 421, 182-187. [CrossRef]

7. Bokov, A.F.; Garg, N.; Ikeno, Y.; Thakur, S.; Musi, N.; DeFronzo, R.A.; Zhang, N.; Erickson, R.C.; Gelfond, J.; Hubbard, G.B.; et al. Does reduced IGF-1R signaling in Igf1r+/- mice alter aging? PLoS ONE 2011, 6, e26891. [CrossRef]

8. Xu, J.; Gontier, G.; Chaker, Z.; Lacube, P.; Dupont, J.; Holzenberger, M. Longevity effect of IGF-1R(+/-) mutation depends on genetic background-specific receptor activation. Aging Cell 2014, 13, 19-28. [CrossRef]

9. Suh, Y.; Atzmon, G.; Cho, M.O.; Hwang, D.; Liu, B.; Leahy, D.J.; Barzilai, N.; Cohen, P. Functionally significant insulin-like growth factor I receptor mutations in centenarians. Proc. Natl. Acad. Sci. USA 2008, 105, 3438-3442. [CrossRef]

10. Tazearslan, C.; Huang, J.; Barzilai, N.; Suh, Y. Impaired IGF1R signaling in cells expressing longevity-associated human IGF1R alleles. Aging Cell 2011, 10, 551-554. [CrossRef]

11. Milman, S.; Huffman, D.M.; Barzilai, N. The somatotropic axis in human aging: Framework for the current state of knowledge and future research. Cell. Metab. 2016, 23, 980-989. [CrossRef] [PubMed]

12. Milman, S.; Atzmon, G.; Huffman, D.M.; Wan, J.; Crandall, J.P.; Cohen, P.; Barzilai, N. Low insulin-like growth factor-1 level predicts survival in humans with exceptional longevity. Aging Cell 2014, 13, 769-771. [CrossRef]

13. Pietra, C.; Takeda, Y.; Tazawa-Ogata, N.; Minami, M.; Yuanfeng, X.; Duus, E.M.; Northrup, R. Anamorelin $\mathrm{HCl}$ (ONO-7643), a novel ghrelin receptor agonist, for the treatment of cancer anorexia-cachexia syndrome: Preclinical profile. J. Cachexia Sarcopenia Muscle 2014, 5, 329-337. [CrossRef] [PubMed]

14. Esposito, A.; Criscitiello, C.; Gelao, L.; Pravettoni, G.; Locatelli, M.; Minchella, I.; Di Leo, M.; Liuzzi, R.; Milani, A.; Massaro, M.; et al. Mechanisms of anorexia-cachexia syndrome and rational for treatment with selective ghrelin receptor agonist. Cancer Treat. Rev. 2015, 41, 793-797. [CrossRef] [PubMed]

15. Borner, T.; Loi, L.; Pietra, C.; Giuliano, C.; Lutz, T.A.; Riediger, T. The ghrelin receptor agonist HM01 mimics the neuronal effects of ghrelin in the arcuate nucleus and attenuates anorexia-cachexia syndrome in tumor-bearing rats. Am. J. Physiol. Regul. Integr. Comp. Physiol. 2016, 311, R89-R96. [CrossRef] [PubMed]

16. Campbell, G.A.; Patrie, J.T.; Gaylinn, B.D.; Thorner, M.O.; Bolton, W.K. Oral ghrelin receptor agonist MK-0677 increases serum insulin-like growth factor 1 in hemodialysis patients: A randomized blinded study. Nephrol. Dial. Transplant. 2018, 33, 523-530. [CrossRef]

17. Florini, J.R.; Ewton, D.Z.; Magri, K.A. Hormones, growth factors, and myogenic differentiation. Annu. Rev. Physiol. 1991, 53, 201-216. [CrossRef] 
18. Molnar, M.Z.; Czira, M.E.; Rudas, A.; Ujszaszi, A.; Haromszeki, B.; Kosa, J.P.; Lakatos, P.; Beko, G.; Sarvary, E.; Varga, M.; et al. Association between the malnutrition-inflammation score and post-transplant anaemia. Nephrol. Dial. Transplant. 2011, 26, 2000-2006. [CrossRef]

19. Molnar, M.Z.; Czira, M.E.; Rudas, A.; Ujszaszi, A.; Lindner, A.; Fornadi, K.; Kiss, I.; Remport, A.; Novak, M.; Kennedy, S.H.; et al. Association of the malnutrition-inflammation score with clinical outcomes in kidney transplant recipients. Am. J. Kidney Dis. 2011, 58, 101-108. [CrossRef]

20. Stam, S.P.; Eisenga, M.F.; Gomes Neto, A.W.; Van Londen, M.; De Meijer, V.E.; Van Beek, A.P.; Gansevoort, R.T.; Bakker, S.J.L. Muscle mass determined from urinary creatinine excretion rate, and muscle performance in renal transplant recipients. J. Cachexia Sarcopenia Muscle 2019, 10, 621-629. [CrossRef]

21. Oterdoom, L.H.; de Vries, A.P.; van Ree, R.M.; Gansevoort, R.T.; van Son, W.J.; van der Heide, J.J.; Navis, G.; de Jong, P.E.; Gans, R.O.; Bakker, S.J. N-terminal pro-B-type natriuretic peptide and mortality in renal transplant recipients versus the general population. Transplantation 2009, 87, 1562-1570. [CrossRef] [PubMed]

22. Oterdoom, L.H.; van Ree, R.M.; de Vries, A.P.; Gansevoort, R.T.; Schouten, J.P.; van Son, W.J.; Homan van der Heide, J.J.; Navis, G.; de Jong, P.E.; Gans, R.O.; et al. Urinary creatinine excretion reflecting muscle mass is a predictor of mortality and graft loss in renal transplant recipients. Transplantation 2008, 86, 391-398. [CrossRef] [PubMed]

23. Said, M.Y.; Deetman, P.E.; de Vries, A.P.; Zelle, D.M.; Gans, R.O.; Navis, G.; Joosten, M.M.; Bakker, S.J. Causal path analyses of the association of protein intake with risk of mortality and graft failure in renal transplant recipients. Clin. Transplant. 2015, 29, 447-457. [CrossRef] [PubMed]

24. Tyrovolas, S.; Koyanagi, A.; Olaya, B.; Ayuso-Mateos, J.L.; Miret, M.; Chatterji, S.; Tobiasz-Adamczyk, B.; Koskinen, S.; Leonardi, M.; Haro, J.M. Factors associated with skeletal muscle mass, sarcopenia, and sarcopenic obesity in older adults: A multi-continent study. J. Cachexia Sarcopenia Muscle 2016, 7, 312-321. [CrossRef]

25. Chu, M.P.; Lieffers, J.; Ghosh, S.; Belch, A.; Chua, N.S.; Fontaine, A.; Sangha, R.; Turner, R.A.; Baracos, V.E.; Sawyer, M.B. Skeletal muscle density is an independent predictor of diffuse large B-cell lymphoma outcomes treated with rituximab-based chemoimmunotherapy. J. Cachexia Sarcopenia Muscle 2017, 8, 298-304. [CrossRef] [PubMed]

26. Makizako, H.; Shimada, H.; Doi, T.; Tsutsumimoto, K.; Lee, S.; Lee, S.C.; Harada, K.; Hotta, R.; Nakakubo, S.; Bae, S.; et al. Age-dependent changes in physical performance and body composition in community-dwelling Japanese older adults. J. Cachexia Sarcopenia Muscle 2017, 8, 607-614. [CrossRef]

27. Van den Berg, E.; Pasch, A.; Westendorp, W.H.; Navis, G.; Brink, E.J.; Gans, R.O.; van Goor, H.; Bakker, S.J. Urinary sulfur metabolites associate with a favorable cardiovascular risk profile and survival benefit in renal transplant recipients. J. Am. Soc. Nephrol. 2014, 25, 1303-1312. [CrossRef]

28. Wendel-Vos, G.C.; Schuit, A.J.; Saris, W.H.; Kromhout, D. Reproducibility and relative validity of the short questionnaire to assess health-enhancing physical activity. J. Clin. Epidemiol. 2003, 56, 1163-1169. [CrossRef]

29. Inker, L.A.; Schmid, C.H.; Tighiouart, H.; Eckfeldt, J.H.; Feldman, H.I.; Greene, T.; Kusek, J.W.; Manzi, J.; Van Lente, F.; Zhang, Y.L.; et al. Estimating glomerular filtration rate from serum creatinine and cystatin C. N. Engl. J. Med. 2012, 367, 20-29. [CrossRef]

30. Klont, F.; Ten Hacken, N.H.T.; Horvatovich, P.; Bakker, S.J.L.; Bischoff, R. Assuring consistent performance of an insulin-like growth factor 1 MALDImmunoassay by monitoring measurement quality indicators. Anal. Chem. 2017, 89, 6188-6195. [CrossRef]

31. Food and Drug Administration (FDA). Guidance for Industry: Bioanalytical Method Validation; The United States Department of Health and Human Services: Washington, DC, USA, 2001.

32. Tubben, A.; Sotomayor, C.G.; Post, A.; Minovic, I.; Frelink, T.; de Borst, M.H.; Said, M.Y.; Douwes, R.M.; van den Berg, E.; Rodrigo, R.; et al. Urinary oxalate excretion and long-term outcomes in kidney transplant recipients. J. Clin. Med. 2019, 8, 2104. [CrossRef] [PubMed]

33. Minović, I.; van der Veen, A.; van Faassen, M.; Riphagen, I.J.; van den Berg, E.; van der Ley, C.; Gomes-Neto, A.W.; Geleijnse, J.M.; Eggersdorfer, M.; Navis, G.J.; et al. Functional vitamin B-6 status and long-term mortality in renal transplant recipients. Am. J. Clin. Nutr. 2017, 106, 1366-1374. [CrossRef] [PubMed]

34. Preacher, K.J.; Hayes, A.F. SPSS and SAS procedures for estimating indirect effects in simple mediation models. Behav. Res. Methods Instrum. Comput. 2004, 36, 717-731. [CrossRef] [PubMed] 
35. Burkitt, W.; Domann, P.; O'Connor, G. Conformational changes in oxidatively stressed monoclonal antibodies studied by hydrogen exchange mass spectrometry. Protein Sci. 2010, 19, 826-835. [CrossRef]

36. Harrell, F.E., Jr.; Lee, K.L.; Califf, R.M.; Pryor, D.B.; Rosati, R.A. Regression modelling strategies for improved prognostic prediction. Stat. Med. 1984, 3, 143-152. [CrossRef]

37. Teppala, S.; Shankar, A.; Sabanayagam, C. Association between IGF-1 and chronic kidney disease among US adults. Clin. Exp. Nephrol. 2010, 14, 440-444. [CrossRef]

38. Wennberg, A.M.V.; Hagen, C.E.; Petersen, R.C.; Mielke, M.M. Trajectories of plasma IGF-1, IGFBP-3, and their ratio in the Mayo Clinic study of aging. Exp. Gerontol. 2018, 106, 67-73. [CrossRef]

39. Chew, J.; Tay, L.; Lim, J.P.; Leung, B.P.; Yeo, A.; Yew, S.; Ding, Y.Y.; Lim, W.S. Serum myostatin and IGF-1 as gender-specific biomarkers of frailty and low muscle mass in community-dwelling older adults. J. Nutr. Health Aging 2019, 23, 979-986. [CrossRef]

40. Kong, A.P.; Wong, G.W.; Choi, K.C.; Ho, C.S.; Chan, M.H.; Lam, C.W.; Tong, P.C.; Ozaki, R.; So, W.Y.; Ma, R.C.; et al. Reference values for serum levels of insulin-like growth factor (IGF-1) and IGF-binding protein 3 (IGFBP-3) and their ratio in Chinese adolescents. Clin. Biochem. 2007, 40, 1093-1099. [CrossRef]

41. Friedrich, N.; Alte, D.; Volzke, H.; Spilcke-Liss, E.; Ludemann, J.; Lerch, M.M.; Kohlmann, T.; Nauck, M.; Wallaschofski, H. Reference ranges of serum IGF-1 and IGFBP-3 levels in a general adult population: Results of the study of health in Pomerania (SHIP). Growth Horm. IGF Res. 2008, 18, 228-237. [CrossRef]

42. Alberti, C.; Chevenne, D.; Mercat, I.; Josserand, E.; Armoogum-Boizeau, P.; Tichet, J.; Leger, J. Serum concentrations of insulin-like growth factor (IGF)-1 and IGF binding protein-3 (IGFBP-3), IGF-1/IGFBP-3 ratio, and markers of bone turnover: Reference values for French children and adolescents and z-score comparability with other references. Clin. Chem. 2011, 57, 1424-1435. [CrossRef] [PubMed]

43. Chanson, P.; Arnoux, A.; Mavromati, M.; Brailly-Tabard, S.; Massart, C.; Young, J.; Piketty, M.L.; Souberbielle, J.C.; VARIETE Investigators. Reference values for IGF-I serum concentrations: Comparison of six immunoassays. J. Clin. Endocrinol. Metab. 2016, 101, 3450-3458. [CrossRef] [PubMed]

44. Bonert, V.; Carmichael, J.; Wu, Z.; Mirocha, J.; Perez, D.A.; Clarke, N.J.; Reitz, R.E.; McPhaul, M.J.; Mamelak, A. Discordance between mass spectrometry and immunometric IGF-1 assay in pituitary disease: A prospective study. Pituitary 2018, 21, 65-75. [CrossRef] [PubMed]

45. Endogenous Hormones and Breast Cancer Collaborative Group; Key, T.J.; Appleby, P.N.; Reeves, G.K.; Roddam, A.W. Insulin-like growth factor 1 (IGF1), IGF binding protein 3 (IGFBP3), and breast cancer risk: Pooled individual data analysis of 17 prospective studies. Lancet Oncol. 2010, 11, 530-542. [CrossRef]

46. Heijboer, A.C.; Blankenstein, M.A.; Kema, I.P.; Buijs, M.M. Accuracy of 6 routine 25-hydroxyvitamin D assays: Influence of vitamin D binding protein concentration. Clin. Chem. 2012, 58, 543-548. [CrossRef]

47. Di Micco, L.; Quinn, R.R.; Ronksley, P.E.; Bellizzi, V.; Lewin, A.M.; Cianciaruso, B.; Ravani, P.; Alberta Kidney Disease Network (AKDN). Urine creatinine excretion and clinical outcomes in CKD. Clin. J. Am. Soc. Nephrol. 2013, 8, 1877-1883. [CrossRef]

48. Kalantari, K.; Bolton, W.K. A good reason to measure 24-h urine creatinine excretion, but not to assess kidney function. Clin. J. Am. Soc. Nephrol. 2013, 8, 1847-1849. [CrossRef]

49. Oterdoom, L.H.; Gansevoort, R.T.; Schouten, J.P.; de Jong, P.E.; Gans, R.O.; Bakker, S.J. Urinary creatinine excretion, an indirect measure of muscle mass, is an independent predictor of cardiovascular disease and mortality in the general population. Atherosclerosis 2009, 207, 534-540. [CrossRef]

50. Yakar, S.; Isaksson, O. Regulation of skeletal growth and mineral acquisition by the GH/IGF-1 axis: Lessons from mouse models. Growth Horm. IGF Res. 2016, 28, 26-42. [CrossRef]

51. Clemmons, D.R. Role of IGF-I in skeletal muscle mass maintenance. Trends Endocrinol. Metab. 2009, 20, 349-356. [CrossRef]

52. Zelle, D.M.; Corpeleijn, E.; Stolk, R.P.; de Greef, M.H.; Gans, R.O.; van der Heide, J.J.; Navis, G.; Bakker, S.J. Low physical activity and risk of cardiovascular and all-cause mortality in renal transplant recipients. Clin. J. Am. Soc. Nephrol. 2011, 6, 898-905. [CrossRef] [PubMed]

53. Rosas, S.E.; Reese, P.P.; Huan, Y.; Doria, C.; Cochetti, P.T.; Doyle, A. Pretransplant physical activity predicts all-cause mortality in kidney transplant recipients. Am. J. Nephrol. 2012, 35, 17-23. [CrossRef] [PubMed]

54. Bellizzi, V.; Cupisti, A.; Capitanini, A.; Calella, P.; D'Alessandro, C. Physical activity and renal transplantation. Kidney Blood Press. Res. 2014, 39, 212-219. [CrossRef] [PubMed]

55. Dunn, S.E.; Burns, J.L.; Michel, R.N. Calcineurin is required for skeletal muscle hypertrophy. J. Biol. Chem. 1999, 274, 21908-21912. [CrossRef] 
56. Michel, R.N.; Dunn, S.E.; Chin, E.R. Calcineurin and skeletal muscle growth. Proc. Nutr. Soc. 2004, 63, 341-349. [CrossRef]

57. Hudson, M.B.; Price, S.R. Calcineurin: A poorly understood regulator of muscle mass. Int. J. Biochem. Cell Biol. 2013, 45, 2173-2178. [CrossRef]

(C) 2020 by the authors. Licensee MDPI, Basel, Switzerland. This article is an open access article distributed under the terms and conditions of the Creative Commons Attribution (CC BY) license (http://creativecommons.org/licenses/by/4.0/). 